\title{
The influence of environmental factors on $\beta$-blockers sampling rates by passive samplers containing carbon nanotubes as a sorbent
}

\author{
Klaudia Godlewska, Aleksandra Jakubus, Monika Paszkiewicz, Piotr Stepnowski \\ Department of Environmental Analysis, Faculty of Chemistry, University of Gdansk, Wita Stwosza 63, Gdansk, Poland \\ Corresponding author: klaudyna999@wp.pl
}

DOI: $10.31708 /$ spi3.18/godl.cns18

\section{Introduction}

Passive samplers are relatively new tools for the isolation and monitoring of micropollutants in the aquatic environment. Since the appearance of the first passive dosimeter used in surface water in 1987, passive sampling devices (PSDs) have quickly become commonplace. Passive techniques have many important advantages, including simplicity of use, low cost, no need to use complicated equipment, no need to supply energy, maintenance-free and the ability to obtain reliable results (Yang et al., 2017). Due to the continuous development of passive sampling methods, currently available samplers enable detection and analysis of chemical compounds at low and very low concentrations. To estimate the time-weighted average (TWA) concentrations of analytes in water basins it is necessary to calibrate dosimeters. It includes the assessment of sampling rates (Rs) for individual compounds. It is also worth noting that Rs for passive samplers depends on the physicochemical properties of analytes (molecular mass, hydrophobicity, solubility) and environmental conditions such as water agitation, salinity, $\mathrm{pH}$ of the sample and the dissolved organic matter (DOM) concentration (Harman, Allan, \& Vermeirssen, 2012).

\section{Materials and Methods}

In connection with the above, the aim of this research was to determine the influence of external factors on $\beta$ blockers Rs, including: metoprolol, nadolol, pindolol, acebutolol, atenolol and propranolol from water samples. As a sorbent in a passive dosimeter, multi-walled carbon nanotubes modified with carboxylic groups $(\mathrm{COOH}-$ MWCNTs) with an outside diameter $<8 \mathrm{~nm}$ was used. The influence of environmental factors, such as sample $\mathrm{pH}$, water agitation, salinity and the dissolved organic matter on the sampling rate of analytes by a passive samplers was investigated. For this purpose, PSDs were placed in a water containing target compounds at a concentration of $2 \mu \mathrm{g} \mathrm{ml}-1$ in glass calibration chambers. A sample of water was taken from each vessel every 2 hours, followed by chromatographic analysis using HPLC-DAD.

\section{Results}

The obtained results indicate that both the salinity of the sample and the water agitation cause a decrease in the Rs value of the tested $\beta$-blockers. On the other hand, the dissolved organic matter or the $\mathrm{pH}$ of the sample does not significantly affect the Rs of analytes.

\section{Discussion}

Taking into account the obtained results, it has been proved that $\mathrm{COOH}-M W C N T$ s can serve as an alternative sorbent for isolation of a selected group of pharmaceuticals from water samples, which is also confirmed by previous studies (Jakubus, Tyma, Stepnowski, \& Paszkiewicz, 2017) in which also managed to use carbon nanotubes as a sorbent in a passive sampler to extract micropollutants from water. It was also shown that the study of the influence of environmental factors on Rs of analytes is necessary during calibration of passive probes in laboratory conditions. Shi et al. (Shi, Zhou, Zhao, Hou, \& Yang, 2014) performed PSDs calibrations to determine antibiotics and hormones in coastal waters. The influence of sample salinity $(0 \%, 14 \%, 35 \%)$ on the Rs of the target analytes was investigated. It was shown that the increase in water salinity caused an increase in the sampling rates of all tested compounds, which is consistent with the results obtained in this research.

\section{References}

Harman, C., Allan, I. J., \& Vermeirssen, E. L. M. (2012). Calibration and use of the polar organic chemical integrative sampler--a critical review.

Environmental Toxicology and Chemistry, 31(12), 2724-2738. https://doi.org/10.1002/etc.2011

Jakubus, A., Tyma, M., Stepnowski, P., \& Paszkiewicz, M. (2017). Application of passive sampling devices based on multi-walled carbon nanotubes for the isolation of selected pharmaceuticals and phenolic compounds in water samples - possibilities and limitations. Talanta, 164, 700-707. https://doi.org/10.1016/j.talanta.2016.09.052

Shi, X., Zhou, J. L., Zhao, H., Hou, L., \& Yang, Y. (2014). Application of passive sampling in 
assessing the occurrence and risk of antibiotics and endocrine disrupting chemicals in the Yangtze Estuary, China. Chemosphere, 111, 344-351. https://doi.org/10.1016/j.chemosphere.2014.03.13 9

Yang, C., Li, Y., Zha, D., Lu, G., Sun, Q., \& Wu, D. (2017). A passive sampling method for assessing the occurrence and risk of organophosphate flame retardants in aquatic environments.

Chemosphere, 167, 1-9.

https://doi.org/10.1016/j.chemosphere.2016.09.14 